\title{
Tissue ascorbic acid and polyol pathway metabolism in experimental diabetes
}

\author{
R. M. Lindsay, N.S.D.Jamieson, S. A. Walker, C. C.McGuigan, W.Smith, J.D. Baird \\ The Metabolic Unit, University of Edinburgh Department of Medicine, Western General Hospital, Edinburgh, UK
}

\begin{abstract}
Summary Previous studies demonstrating reduced plasma concentrations of ascorbic acid (AA) in diabetes and interactions between this vitamin and biochemical mechanisms such as synthesis of structural proteins, oxidative stress, polyol pathway and nonenzymatic glycation of proteins suggest that disturbed AA metabolism may be important in the pathogenesis of diabetic microangiopathy. However, limited information is available on the concentration of AA in tissues which develop diabetic complications. This study demonstrates reduced renal but not sciatic nerve or plasma AA concentration in two animal models of insulin-dependent diabetes mellitus, namely the STZ-diabetic rat and the spontaneously diabetic BB rat. Decreased lens AA concentration was also observed in STZ-diabetic rats. Improvement of glycaemic control by insulin treatment (albeit insufficient to achieve normoglycaemia) partially corrected lens and renal AA concentration in STZ-diabetic rats. AA treatment increased kidney and lens AA concentrations of STZ-diabetic and non-diabetic rats and corrected the abnormalities observed for un-
\end{abstract}

treated diabetic rats. Sciatic nerve AA concentration was not increased by AA treatment in any group. Tissue ratios of dehydroascorbic acid (DHAA)/AA, one index of oxidative stress, were not different between the diabetic and non-diabetic groups and were unaltered by AA supplementation. AA treatment of STZ-diabetic rats had no effect on elevated tissue concentrations of glucose, sorbitol and fructose or reduced myo-inositol concentration. The effect of reduced tissue AA levels in diabetes on either collagen synthesis or ability to combat increased free radical production is not known. However, correction of abnormal kidney and lens AA concentrations in experimental diabetes by AA supplementation suggests that if AA does have a role in the development or progression of the renal and ocular complications of diabetes, this treatment could be beneficial. [Diabetologia (1998) 41: 516-523]

Keywords Ascorbic acid, polyol pathway, streptozotocin-diabetic rat, spontaneously diabetic BB rat, oxidative stress
Abnormalities of collagen synthesis [1] and increased oxidative stress [2] have been implicated in the pathogenesis of diabetic microangiopathy. Since ascorbic

Received: 6 October 1997 and in final revised form: 15 January 1998

Corresponding author: Dr. R. M. Lindsay, The Metabolic Unit, University of Edinburgh Department of Medicine, Western General Hospital, Edinburgh EH4 2XU, UK

Abbreviations: AA, Ascorbic acid; DHAA, dehydroascorbic acid; STZ, streptozotocin; BB, Bio-Breeding; IDDM, insulindependent diabetes mellitus. acid (AA; vitamin C) is an essential cofactor for prolyl hydroxylase, a key enzyme in the biosynthesis of collagen and is also an important antioxidant [3], AA metabolism may link these processes.

Decreased plasma AA concentrations and increased turnover of AA to the oxidised metabolite dehydroascorbic acid (DHAA) have been reported in diabetic subjects [4-10], particularly in patients with poor glycaemic control [11] and/or microangiopathy $[12,13]$. Although (i) leucocyte AA concentration is reduced following intravenous glucose [14], (ii) in vitro cell culture studies [15-18] demonstrate competitive cellular uptake of glucose and AA and (iii) in 
vivo studies have suggested a reciprocal relationship between circulating AA concentration and both the polyol pathway [19-22] and non-enzymatic glycation of proteins [23-25], limited information is available on the effect of diabetes on tissue AA concentrations $[26,27]$.

The aims of our study were to measure AA concentration in both plasma and some tissues relevant to the development of the long-term complications of diabetes (kidney, lens and sciatic nerve), determine the principal metabolites of the polyol pathway in these tissues and study the effect of insulin treatment and/or AA supplementation on these parameters in rats with STZ-diabetes.

In addition, we have measured AA concentration and polyol pathway metabolites in kidney and sciatic nerve in another experimental model of insulin-dependent diabetes mellitus (IDDM), that is the spontaneously diabetic BB rat [28].

\section{Materials and methods}

Materials. AA, STZ, ascorbate oxidase and 1, 2-phenylene diamine were supplied by Sigma Chemical Company Ltd., Poole, UK. Metaphosphoric acid was obtained from Aldrich Chemical Company Ltd., Gillingham, UK. Tri-Sil derivatisation reagent was obtained from Pierce and Warriner (UK) Limited, Chester, UK.

Wistar Han rats. Diabetes was induced in age-matched (mean \pm SEM age $=95 \pm 0.4$ days) Wistar Han rats $(n=21)$ by a single intravenous injection ( $70 \mathrm{mg} / \mathrm{kg}$ body weight) of STZ (Sigma). Random blood glucose concentration was measured (Reflolux S meter, Boehringer Mannheim, Lewes, UK) 3 days later. The criterion for diagnosing an animal as diabetic was a blood glucose concentration greater than $18 \mathrm{mmol} / \mathrm{l}$.

$B B$ rats. A breeding colony of $\mathrm{BB}$ rats was established in Edinburgh in 1982 from a small nucleus of animals (3 male and 4 female) kindly donated by Dr. P. Thibert from the original BB colony in Ottawa. The $\mathrm{BB} / \mathrm{E}$ colony consists of two lines created by selectively breeding for and against diabetes and these two lines have now been through 24 generations of strict brother/sister mating on site and have had their inbred status confirmed by skin grafting experiments. All animals are weighed twice weekly from 40 days of age. If they fail to gain weight or lose weight, they are tested for glycosuria (Multistix SG reagent strips, Bayer Diagnostics UK Ltd., Basingstoke, UK). If glycosuria is detected, the blood glucose concentration is measured (Exactech blood glucose meter, Medisense Britain Ltd., Birmingham, UK) on a blood sample obtained by tail tipping without anaesthesia. In the Edinburgh BB rat colony, a blood glucose concentration greater than $18 \mathrm{mmol} / \mathrm{l}$ is invariably associated with ketonuria, weight loss and the need for daily injection of insulin (Bovine Ultratard U40, Novo Nordisk, Denmark) to survive and these parameters constitute our criterion for classifying an animal as having IDDM. In the high incidence, diabetes - prone mainline the incidence of IDDM is $50-60 \%$ and the mean \pm SD age at onset of diabetes is $96 \pm 18$ days. In the diabetes - resistant subline the incidence of diabetes is less than $1 \%$.
All rats were maintained at $20^{\circ} \mathrm{C}$ on $12 \mathrm{~h}$ light/dark cycles and were fed SDS rat and mouse No. 1 expanded feed containing $11 \mathrm{mg} \mathrm{AA} / \mathrm{kg}$ (Special Diet Services, Witham, UK).

Experimental protocol for Wistar Han rats. Immediately after diagnosis of diabetes, STZ-diabetic rats were randomised to the following four groups : untreated $(n=6)$, insulin-treated $(n=4)$, AA-treated $(n=6)$ and insulin/AA-treated $(n=5)$. Insulin treatment involved a single daily subcutaneous injection of insulin (Bovine Ultratard U40, Novo Nordisk, Denmark; mean \pm SEM daily dose $=2.5 \pm 0.2 \mathrm{U})$. AA was administered in the drinking water (solutions prepared daily) and the individual daily dose received by each rat calculated by measuring water consumption. The aqueous stability of AA in the drinking water during the $24 \mathrm{~h}$ period before replacement with fresh solution was $94 \%$. The mean \pm SEM daily dose of AA was $133 \pm 8 \mathrm{mg}$ and the duration of treatment was 4 weeks, a treatment regimen similar to previous studies [20,29]. Mean \pm SEM blood glucose concentration (Reflolux S meter, Boehringer Mannheim, Lewes, UK), measured between 09.00 and $10.00 \mathrm{~h}$ towards the end of the study, was $16.6 \pm 1.0 \mathrm{mmol} / \mathrm{l}$ and $26.2 \pm 1.2 \mathrm{mmol} / \mathrm{l}$ for diabetic rats treated or untreated with insulin respectively. Treatment with AA did not have any effect on blood glucose concentration $(17.2 \pm 1.1 \mathrm{mmol} / \mathrm{l}$ and $26.6 \pm 1.1 \mathrm{mmol} / \mathrm{l}$ respectively). In addition non-diabetic rats were randomised to either untreated $(n=10)$ or AA-treated $(n=11)$ groups.

At the end of the 4 week treatment period, all animals were asphyxiated in a carbon dioxide chamber prior to collection of samples of blood, kidney, sciatic nerve and lens. Blood samples (collected into lithium-heparin anticoagulant containers) were centrifuged immediately at $4{ }^{\circ} \mathrm{C}$. Plasma was deproteinised using $5 \%$ metaphosphoric acid. The other tissues were frozen in liquid nitrogen and stored at $-70^{\circ} \mathrm{C}$ prior to analysis of AA, DHAA and polyol pathway metabolites.

Experimental protocol for $B B$ rats. Age-matched $(174 \pm 5 \mathrm{~d})$ non-diabetic $(n=10)$ and diabetic (duration of diabetes $=79$ $\pm 4 \mathrm{~d}$; daily insulin dose $=3.1 \pm 0.1 \mathrm{U} ; n=10) \mathrm{BB} / \mathrm{E}$ rats were anaesthetised using halothane and samples of blood, kidney and sciatic nerve collected and stored as described above.

$A A$ analysis. Kidney samples were homogenised in 5\% metaphosphoric acid. Lens and sciatic nerve samples were lyophilised, powdered using a microdismembrator (B. Braun, Melsungun AG, Germany) and deproteinised with $5 \%$ metaphosphoric acid. Tissue concentrations of total AA (i.e. free AA + DHAA) were determined using a fluorimetric method described previously in detail [30,31], adapted for use on a Cobas Bio centrifugal fast analyser [32] (Hoffman-La Roche, Welwyn Garden City, UK). DHAA concentrations were also determined by omission of ascorbate oxidase. AA concentration was used as an index of antioxidant status and the ratio of DHAA/AA (\%) was used as a measure of oxidative stress $[12,13]$. The inter-assay coefficients of variation for AA and DHAA were $2.7 \%$ and $6.1 \%$, respectively. Mean recoveries of added AA or DHAA from spiked tissue extracts were $100.4 \pm 1.3 \%(n=8)$ and $101.7 \pm 2.5 \%(n=8)$, respectively. Comparison of the results of simultaneous analysis of AA concentration in 30 plasma samples by the fluorimetric method used in this study and an HPLC method using ultraviolet detection [33] showed significant correlation $\left(r^{2}=0.975, p<0.001\right)$.

Analysis of polyol pathway metabolites. Tissue concentrations of sorbitol, fructose, glucose and myo-inositol were determined by capillary gas chromatography of trimethylsilyl ether derivatives [34]. 
Table 1. Characteristics of non-diabetic and STZ-diabetic rats studied

\begin{tabular}{|c|c|c|c|c|c|c|}
\hline & Non-diabetic & $\begin{array}{l}\text { STZ-diabetic } \\
\text { (insulin-treated) }\end{array}$ & STZ-diabetic & $\begin{array}{l}\text { Non-diabetic } \\
\text { (AA-treated) }\end{array}$ & $\begin{array}{l}\text { STZ-diabetic } \\
\text { (insulin- and } \\
\text { AA-treated) }\end{array}$ & $\begin{array}{l}\text { STZ-diabetic } \\
\text { (AA-treated) }\end{array}$ \\
\hline Initial body weight (g) & $321 \pm 18$ & $319 \pm 26$ & $332 \pm 22$ & $312 \pm 17$ & $312 \pm 20$ & $326 \pm 33$ \\
\hline Final body weight (g) & $395 \pm 29$ & $352 \pm 20$ & $294 \pm 16^{\mathrm{a}, \mathrm{c}}$ & $384 \pm 25$ & $345 \pm 14$ & $282 \pm 18^{\mathrm{a}, \mathrm{c}}$ \\
\hline $\begin{array}{l}\text { Initial glycated haemoglobin } \\
\text { concentration }(\%)\end{array}$ & $2.4 \pm 0.1$ & $2.4 \pm 0.2$ & $2.6 \pm 0.1$ & $2.4 \pm 0.1$ & $2.6 \pm 0.4$ & $2.7 \pm 0.4$ \\
\hline $\begin{array}{l}\text { Final glycated haemoglobin } \\
\text { concentration }(\%)\end{array}$ & $2.8 \pm 0.2$ & $7.7 \pm 0.6^{b}$ & $11.9 \pm 1.4^{\mathrm{b}, \mathrm{c}}$ & $2.4 \pm 0.2$ & $8.2 \pm 0.8^{b}$ & $14.4 \pm 1.1^{\mathrm{b}, \mathrm{d}}$ \\
\hline $\begin{array}{l}\text { Initial plasma AA concen- } \\
\text { tration }(\mu \mathrm{mol} / \mathrm{l})\end{array}$ & $56.4 \pm 3.5$ & $50.5 \pm 8.5$ & $53.4 \pm 8.2$ & $40.7 \pm 5.2$ & $50.0 \pm 6.9$ & $47.8 \pm 6.9$ \\
\hline $\begin{array}{l}\text { Final plasma AA concen- } \\
\text { tration }(\mu \mathrm{mol} / \mathrm{l})\end{array}$ & $67.8 \pm 5.8$ & $46.6 \pm 10.1$ & $58.0 \pm 7.0$ & $103.2 \pm 11.9$ & $158.6 \pm 22.5$ & $116.4 \pm 18.6$ \\
\hline Number of animals & 10 & 4 & 6 & 11 & 5 & 6 \\
\hline
\end{tabular}

Glycated haemoglobin analysis. Glycated haemoglobin level of $\mathrm{BB}$ rats was measured by electroendosmosis as described previously [35]. Glycated haemoglobin level of STZ-diabetic rats was measured by boronic acid affinity chromatography (Glycotest II, Pierce and Warriner (UK) Limited, Chester, UK) as AA treatment interferes with measurement of glycated haemoglobin by electroendosmosis [25].

Analysis of plasma glucose. A Beckman Synchron AS4 automated analyser system (Beckman-RIIC, High Wycombe, UK) was used to determine plasma glucose concentration.

Statistical analysis. Means and standard errors of the mean (SEM) were calculated for all data. The significance of difference between means was determined using either two tailed unpaired Student's $t$-test or paired $t$-test as appropriate.

\section{Results}

Wistar Han rats. Mean body weight, glycated haemoglobin and plasma AA concentration in all the rats studied at the beginning and end of the study are shown in Table 1 . There were no significant differences in these parameters between the six groups at the start of the study. Non-diabetic rats gained weight $(p<0.001)$ during the study which was not affected by AA supplementation. The body weight of insulin-treated STZ-diabetic rats (both untreated and AA-supplemented groups) also increased $(p<0.01)$ but to a lesser extent. In contrast, STZ-diabetic rats maintained without insulin injections lost weight $(p<0.01)$ during the study, irrespective of AA treatment. Mean glycated haemoglobin was raised $(p<0.001)$ in all diabetic rats compared with non-diabetic rats and was not affected by AA treatment. Although treatment with insulin lowered $(p<0.05)$ mean glycated haemoglobin value compared with untreated diabetic rats, it was still higher $(p<0.001)$ than that in nondiabetic animals.
Plasma AA concentration. There was no significant difference in mean AA concentration between nondiabetic and both diabetic groups. Although AA treatment increased $(p<0.02)$ plasma AA concentration in all three groups, the differences between the three groups were still insignificant (Table 1, Fig. 1).

Kidney AA concentration. Mean AA concentration was lower in both groups of diabetic rats $(p<0.02$ and $p<0.01$ for insulin-treated diabetic and insulinuntreated diabetic rats, respectively) compared with non-diabetic rats. Renal AA concentration was increased in all three groups following AA treatment $(p<0.01, p<0.001$ and $p<0.001$ for non-diabetic, insulin-treated diabetic and insulin-untreated diabetic rats, respectively). Renal AA concentration was lower $(p<0.05)$ in AA-treated diabetic rats maintained without insulin compared to AA/insulin-treated diabetic rats (Fig. 1).

Lens AA concentration. Mean AA concentration was lower in both groups of diabetic rats $(p<0.01$ and $p<0.001$ for insulin-treated diabetic and insulin-untreated diabetic rats, respectively) compared with non-diabetic rats. The lens concentration of AA was lower $(p<0.02)$ in diabetic rats maintained without insulin compared with insulin-treated diabetic animals. Lens AA concentration was increased in all three groups following AA treatment $(p<0.05$, $p<0.02$ and $p<0.02$ for non-diabetic, insulin-treated diabetic and insulin-untreated diabetic rats, respectively). Lens AA concentration was lower in AAtreated diabetic rats maintained without insulin compared with AA-treated non-diabetic $(p<0.001)$ and AA/insulin-treated diabetic $(p<0.05)$ rats (Fig. 1). However, one AA-treated diabetic rat had a lens AA concentration $(1599 \mathrm{pmol} / \mathrm{mg})$ higher $(p<0.001)$ than the other animals in this group and was omitted from the data presented in Figure 1. 

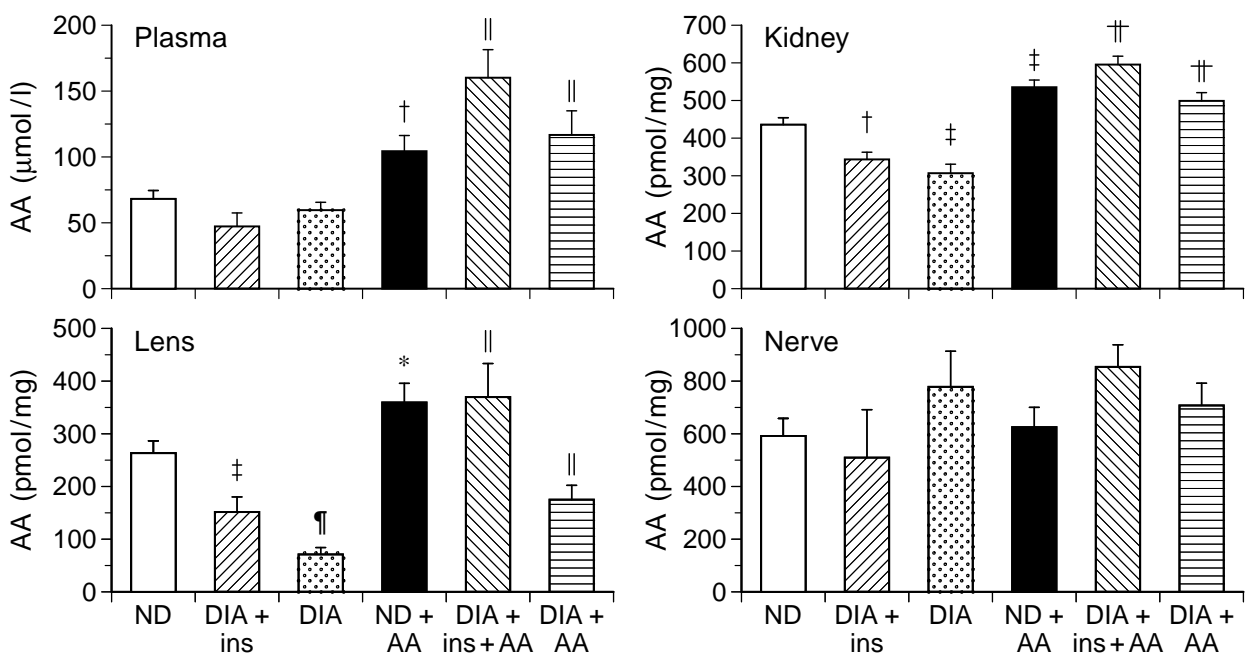

Fig. 1. Effect of ascorbic acid (AA) supplementation on tissue ascorbic acid concentration in non-diabetic (ND) and streptozotocin-induced diabetic (DIA) rats. Mean \pm SEM; ins : insulin-treated; $* p<0.05,+p<0.02$, $\neq p<0.01, \uparrow p<0.001$ compared with untreated non-diabetic rats; $\| p<0.02$, $\# p<0.001$ compared to untreated STZ-diabetic rats

Sciatic nerve AA concentration. There was no difference in mean AA concentration between non-diabetic and both diabetic groups. Sciatic nerve AA content was not significantly increased in any group following AA treatment (Fig.1).

Oxidative stress in plasma, kidney and sciatic nerve. There was no difference in the ratio of DHAA/AA in these tissues between non-diabetic and any of the diabetic groups (Fig.2). AA treatment reduced $(p<0.05)$ the mean plasma value of the percentage of DHAA/AA in insulin-treated STZ-diabetic rats but had no effect in all other cases (Fig. 2). The ratio of DHAA/AA in lens could not be calculated due to insufficient sample available for measurement of both AA and DHAA.

Tissue polyol pathway metabolite concentrations. Tissue glucose, sorbitol and fructose concentrations were elevated $(p<0.001)$ in STZ-diabetic rats not maintained on insulin compared with non-diabetic rats. Although insulin treatment of diabetic rats reduced $(p<0.05)$ sciatic nerve and lens concentrations of these metabolites compared with untreated diabetic rats, these values were still higher $(p<0.05)$ than those for non-diabetic animals. Kidney concentrations of glucose, sorbitol and fructose in insulintreated STZ-diabetic rats were lower (but not significantly so) compared with STZ-diabetic rats not maintained on insulin and were higher $(p<0.05)$ than values for non-diabetic rats. Tissue myo-inositol concentrations in STZ-diabetic rats not maintained
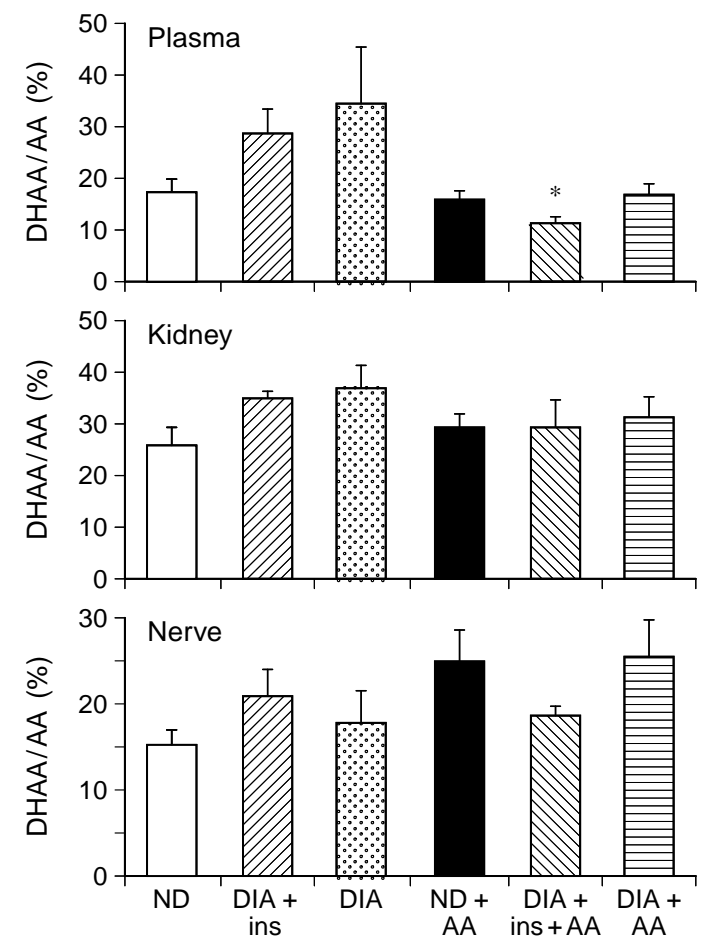

Fig. 2. Effect of ascorbic acid (AA) supplementation on tissue ratios of dehydroascorbic acid (DHAA)/AA in non-diabetic (ND) and streptozotocin-induced diabetic (DIA) rats. Mean \pm SEM; ins : insulin-treated; ${ }^{*} p<0.05$ compared with untreated, insulin-treated STZ-diabetic group

on insulin were lower $(p<0.05)$ than non-diabetic rats. Treatment with insulin normalised myo-inositol levels in sciatic nerve and kidney and increased but did not correct lens concentrations of this compound. AA supplementation did not affect tissue concentrations of glucose, sorbitol, fructose or myo-inositol (Table 2).

$B B$ rats. Mean body weight and plasma glucose concentration were lower in diabetic than non-diabetic $\mathrm{BB} / \mathrm{E}$ rats but not significantly so. Mean glycated 
Table 2. Effect of ascorbic acid (AA) supplementation on tissue concentrations of polyol pathway metabolites in non-diabetic and STZ-diabetic rats

\begin{tabular}{|c|c|c|c|c|c|c|c|}
\hline & & Non-diabet & & STZ-diabetic & & & \\
\hline Insulin $\mathrm{t}_{\mathrm{I}}$ & ment & - & - & - & - & + & + \\
\hline AA supp & nentation & - & + & - & + & - & + \\
\hline $\mathrm{n}$ & & 10 & 11 & 6 & 6 & 4 & 5 \\
\hline Tissue & $\begin{array}{l}\text { Metabolite } \\
\text { (nmol/g tissue) }\end{array}$ & & & & & & \\
\hline $\begin{array}{l}\text { Sciatic } \\
\text { nerve }\end{array}$ & $\begin{array}{l}\text { glucose } \\
\text { sorbitol } \\
\text { fructose } \\
\text { myo-inositol }\end{array}$ & $\begin{array}{c}802 \pm 124 \\
278 \pm 28 \\
668 \pm 49 \\
3523 \pm 341\end{array}$ & $\begin{array}{c}766 \pm 113 \\
303 \pm 21 \\
785 \pm 74 \\
3690 \pm 250\end{array}$ & $\begin{array}{l}5777 \pm 672^{\mathrm{c}, \mathrm{d}} \\
2975 \pm 300^{\mathrm{c}, \mathrm{d}} \\
4805 \pm 177^{\mathrm{c}, \mathrm{f}} \\
2346 \pm 151^{\mathrm{b}, \mathrm{d}}\end{array}$ & $\begin{array}{l}7541 \pm 515^{\mathrm{c}, \mathrm{e}} \\
2377 \pm 215^{\mathrm{c}, \mathrm{d}} \\
5142 \pm 382^{\mathrm{c}, \mathrm{e}} \\
2398 \pm 216^{\mathrm{b}}\end{array}$ & $\begin{array}{l}3066 \pm 614^{\mathrm{b}} \\
1419 \pm 405^{\mathrm{a}} \\
2893 \pm 209^{\mathrm{a}} \\
2896 \pm 175\end{array}$ & $\begin{array}{l}3786 \pm 627^{\mathrm{c}} \\
1217 \pm 349^{\mathrm{a}} \\
2808 \pm 405^{\mathrm{a}} \\
3065 \pm 278\end{array}$ \\
\hline Kidney & $\begin{array}{l}\text { glucose } \\
\text { sorbitol } \\
\text { fructose } \\
\text { myo-inositol }\end{array}$ & $\begin{array}{c}3316 \pm 63 \\
142 \pm 14 \\
409 \pm 9 \\
3916 \pm 190\end{array}$ & $\begin{array}{c}3019 \pm 147 \\
201 \pm 33 \\
354 \pm 12 \\
4179 \pm 290\end{array}$ & $\begin{array}{c}10425 \pm 837^{\mathrm{c}, \mathrm{d}} \\
624 \pm 112^{\mathrm{c}} \\
604 \pm 35^{\mathrm{c}} \\
3103 \pm 224^{\mathrm{a}}\end{array}$ & $\begin{aligned} 10657 & \pm 743^{\mathrm{c}} \\
614 & \pm 67^{\mathrm{c}} \\
616 & \pm 48^{\mathrm{c}} \\
3299 & \pm 183^{\mathrm{a}}\end{aligned}$ & $\begin{array}{c}7013 \pm 965^{\mathrm{b}} \\
396 \pm 85^{\mathrm{a}} \\
525 \pm 39^{\mathrm{a}} \\
3654 \pm 285\end{array}$ & $\begin{aligned} 7666 & \pm 1153^{\mathrm{b}} \\
411 & \pm 77^{\mathrm{d}} \\
530 & \pm 33^{\mathrm{c}} \\
3685 & \pm 148\end{aligned}$ \\
\hline Lens & $\begin{array}{l}\text { glucose } \\
\text { sorbitol } \\
\text { fructose } \\
\text { myo-inositol }\end{array}$ & $\begin{array}{c}69 \pm 5 \\
278 \pm 18 \\
238 \pm 16 \\
1136 \pm 55\end{array}$ & $\begin{array}{c}72 \pm 7 \\
276 \pm 27 \\
260 \pm 18 \\
1052 \pm 73\end{array}$ & $\begin{aligned} 2005 & \pm 214^{\mathrm{c}} \\
22659 & \pm 2723^{\mathrm{c}, \mathrm{f}} \\
8404 & \pm 491^{\mathrm{c}, \mathrm{f}} \\
137 & \pm 11^{\mathrm{c}, \mathrm{f}}\end{aligned}$ & $\begin{aligned} 2536 & \pm 541^{\mathrm{c}, \mathrm{d}} \\
24096 & \pm 3129^{\mathrm{c}, \mathrm{f}} \\
8976 & \pm 516^{\mathrm{c}, \mathrm{f}} \\
169 & \pm 25^{\mathrm{c} f}\end{aligned}$ & $\begin{array}{r}930 \pm 317^{\mathrm{a}} \\
5358 \pm 573^{\mathrm{c}} \\
3698 \pm 328^{\mathrm{c}} \\
750 \pm 116^{\mathrm{a}}\end{array}$ & $\begin{array}{r}955 \pm 336^{\mathrm{a}} \\
4897 \pm 247^{\mathrm{c}} \\
3432 \pm 324^{\mathrm{c}} \\
921 \pm 102^{\mathrm{a}}\end{array}$ \\
\hline
\end{tabular}

Table 3. Characteristics of diabetic and non-diabetic $\mathrm{BB} / \mathrm{E}$ rats studied

\begin{tabular}{lll}
\hline & Non-diabetic & Diabetic \\
\hline Body weight $(\mathrm{g})$ & $340 \pm 26$ & $297 \pm 22$ \\
Plasma glucose concentration $(\mathrm{mmol} / \mathrm{l})$ & $7.4 \pm 0.2$ & $6.3 \pm 1.5$ \\
Glycated haemoglobin $(\%)$ & $4.9 \pm 0.2$ & $6.0 \pm 0.3^{\mathrm{a}}$ \\
Number of animals & 10 & 10 \\
\hline
\end{tabular}

Mean \pm SEM

${ }^{a} p<0.02$ compared with non-diabetic group

haemoglobin was higher $(p<0.02)$ in diabetic than non-diabetic $\mathrm{BB} / \mathrm{E}$ rats (Table 3 ).

Tissue AA concentration. Mean plasma AA concentration was not significantly different between diabetic and non-diabetic BB/E rats (Fig.3). As in STZ-diabetic rats, the mean renal AA concentration was lower $(p<0.02)$ in diabetic than non-diabetic $\mathrm{BB} / \mathrm{E}$ rats and there was no difference in sciatic nerve AA content between the two groups. However, two diabetic rats had sciatic nerve AA concentrations of 1940 and $3890 \mathrm{pmol} / \mathrm{mg}$ which were excluded from Figure 3 since these values exceeded the $99 \%$ confidence limits for the other values in this group. Tissue percentage DHAA/AA values were not significantly different between the two groups (Fig. 3).

Tissue polyol pathway metabolite concentrations. Tissue concentrations of glucose, sorbitol, fructose and myo-inositol were not significantly different between diabetic and non-diabetic $\mathrm{BB} / \mathrm{E}$ rats (Table 4).
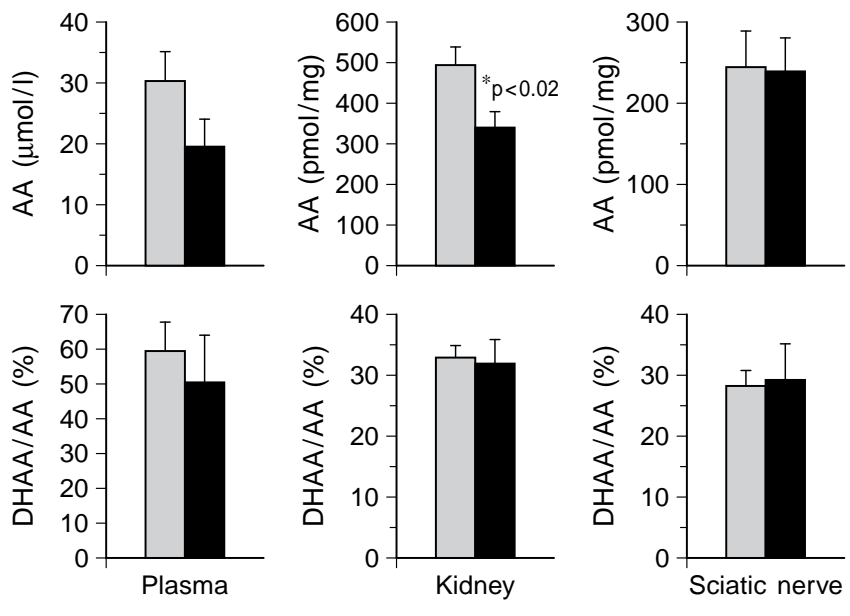

Non-diabetic $(n=10)$

Diabetic $(n=8)$

Fig. 3. Tissue concentration of ascorbic acid (AA) and ratio of dehydroascorbic acid (DHAA)/AA in non-diabetic and diabetic $\mathrm{BB} / \mathrm{E}$ rats. Mean $\pm \mathrm{SEM} ; * p<0.02$ compared with nondiabetic $\mathrm{BB} / \mathrm{E}$ rats

\section{Discussion}

Previous studies demonstrating reduced plasma concentrations of AA in diabetes [6-9, 11-13, 19, 20, 26] and interactions between this vitamin and biochemical mechanisms such as synthesis of structural proteins [19], oxidative stress [5-8, 12, 13, 29], polyol pathway [19-22] and non-enzymatic glycation of proteins [23-25] have suggested that disturbed AA metabolism may be important in the pathogenesis of diabetic microangiopathy. However, with the exception 
Table 4. Kidney and sciatic nerve polyol concentrations in non-diabetic and spontaneously diabetic BB/E rats

\begin{tabular}{llcc}
\hline Tissue & $\begin{array}{l}\text { Metabolite } \\
\text { (nmol/g tissue) }\end{array}$ & Non-diabetic & Diabetic \\
\hline Kidney & glucose & $2260 \pm 169$ & $2945 \pm 360$ \\
& Sorbitol & $255 \pm 46$ & $357 \pm 66$ \\
& fructose & $493 \pm 45$ & $581 \pm 44$ \\
& myo-inositol & $3767 \pm 261$ & $4084 \pm 348$ \\
Sciatic nerve & glucose & $648 \pm 46$ & $644 \pm 65$ \\
& sorbitol & $225 \pm 16$ & $263 \pm 22$ \\
& fructose & $501 \pm 14$ & $675 \pm 71$ \\
& myo-inositol & $3192 \pm 286$ & $2904 \pm 347$ \\
\hline
\end{tabular}

Mean \pm SEM

of one study investigating AA content in diabetic rat lens [27] and one short preliminary communication [26], the effect of diabetes on AA concentrations in tissues which develop diabetic vascular complications has not been reported. This study demonstrates reduced renal AA concentration, but not sciatic nerve AA concentration, in both animal models of diabetes studied and decreased lens AA concentration in STZ-diabetic rats.

The reduced renal and lens concentrations in diabetes confirms previous studies in STZ-diabetic rats [26, 27]. DiMattio also demonstrated that active transport of AA into lens epithelium is impaired in STZ-diabetic rats and guinea pigs [36]. Cataractogenesis in non-diabetic human subjects is associated with reduced AA and elevated DHAA levels in lens [37] and dietary AA supplementation inhibits galactoseinduced cataractogenesis in rats [38] and guinea pigs [39]. Reduced lens glutathione concentration in STZ-diabetic rats [40-42], possibly as a consequence of elevated polyol pathway activity, may contribute to depletion of AA in this tissue.

The reduced renal and lens AA concentrations of diabetic rats were observed in the absence of differences in plasma AA concentration. Previous studies have observed either unchanged [27] or reduced $[11,26,29]$ plasma AA concentrations in STZ-diabetic rats not treated with insulin. The only previous experimental study to investigate the effect of insulin treatment reported normalisation of reduced plasma AA concentration in insulin-treated STZ-diabetic rats [29]. Clinical studies reporting reduced plasma AA concentration in diabetic patients with poor glycaemic control [11] or microangiopathy [12, 13] also indicate the important role of glycaemic control. The insignificant difference in plasma AA concentration between the non-diabetic and wellcontrolled diabetic $\mathrm{BB} / \mathrm{E}$ rats currently studied provides further support for this hypothesis. However, the failure to normalise diabetes-associated abnormalities in tissue AA content by insulin treatment, particularly in the well-controlled diabetic $\mathrm{BB} / \mathrm{E}$ rats studied, suggests that the influence of glycaemic control on AA metabolism in these tissues is more limited.

Although most previous studies on AA metabolism in experimental diabetes have not measured DHAA [19, 20], Young et al. [29] reported no difference in plasma DHAA/AA ratios in non-diabetic, STZ-diabetic and AA-treated STZ-diabetic rats. We observed similar results except that AA treatment reduced the plasma DHAA/AA ratio in insulin-treated STZ-diabetic rats. AA supplementation of human subjects (diabetic and non-diabetic) also reduced the ratio of DHAA/AA in plasma [12]. Although the insignificant difference in renal DHAA/AA ratios between non-diabetic and STZ-diabetic rats suggests no difference in the degree of endogenous oxidative stress in these groups similar to that described in a preliminary study [26], the possibly impaired capacity of diabetic rats to combat increased production of free radical species due to reduced renal and lens AA concentrations remains to be determined.

Candidate mechanisms by which reduced tissue AA concentration could be involved in the development of diabetes-induced vascular damage include increased polyol pathway activity [19-22], non-enzymatic glycation of proteins [23-25], elevated oxidative stress [2] and abnormalities of collagen synthesis [1]. We investigated tissue polyol pathway metabolism since previous clinical studies reported an inverse relationship between erythrocyte concentrations of sorbitol and AA [21] and inhibition of erythrocyte sorbitol production by AA treatment [21,22]. Although we observed relationships between these compounds in lens $(r=0.577, p<0.001)$ and kidney $(r=0.331, p<0.05)$ but not sciatic nerve $(r=0.213$, $p>0.1)$ samples from non-diabetic, insulin-treated STZ-diabetic and insulin-untreated STZ-diabetic rats, AA treatment had no effect on tissue sorbitol production. The reduced renal AA concentration of our well-controlled diabetic $\mathrm{BB} / \mathrm{E}$ rats in which polyol pathway metabolism is normal also suggests a limited impact of polyol pathway intervention on tissue AA concentration.

AA has also previously been shown to reduce nonenzymatic glycation of bovine serum albumin [23] and collagen [24] in vitro and of albumin and haemoglobin in human non-diabetic subjects in vivo [25]. Although we observed no effect of AA treatment on glycated haemoglobin levels of non-diabetic or STZdiabetic rats, we suggest that further studies on the effect of AA treatment on non-enzymatic glycation of intra-cellular proteins within tissues which develop diabetic complications are necessary.

In contrast to the other tissues, we observed no significant difference in sciatic nerve AA concentration between non-diabetic and diabetic rats and no effect of AA treatment of STZ-diabetic rats on nerve AA content. These inter-tissue differences may reflect differences in AA uptake and storage. Our results 
suggest that although increased oxidative stress may be involved in the pathogenesis of experimental diabetic neuropathy [43-45] the role of disturbed AA metabolism is likely to be minor, a hypothesis supported by the limited efficiency of AA treatment in preventing neurovascular dysfunction in STZ-diabetic rats [45].

The reduced renal and lens AA concentrations in the animal models of diabetes studied suggest that endogenous AA synthesis in the rat cannot compensate for these diabetes-induced abnormalities in AA metabolism. Since human subjects are unable to synthesise AA [3] it may be anticipated that greater differences in tissue AA concentration may be observed in human diabetic and non-diabetic subjects. The disturbed metabolism of AA in diabetes and its prevention by AA treatment coupled with the adverse effects of AA deficiency [3] and lack of toxicity of this vitamin [46] suggest that AA treatment of diabetic patients could represent an inexpensive and safe adjunct to conventional treatment. However, the possibility that large doses of AA may have pro-oxidant effects warrants caution [29]. Further investigation is clearly required to fully determine the role of AA metabolism in the pathogenesis of diabetic microvascular disease and any dose-dependency of the antioxidant effect of AA.

Acknowledgements. We are grateful to the Cunningham Trust for supporting the Edinburgh colony of BB rats. The financial support of NSDJ and CCM by Hoffman-La Roche and the Scottish Office Home and Health Department respectively is gratefully acknowledged. We thank Dr. GG Duthie and Ms. MA Ross of the Rowett Research Institute in Aberdeen, UK for their collaboration in HPLC analysis of AA.

\section{References}

1. Schnider S, Kohn RR (1981) The effects of age and diabetes mellitus on the solubility and nonenzymatic glucosylation of human skin collagen. J Clin Invest 67: 1630-1635

2. Baynes JW (1991) Role of oxidative stress in development of complications of diabetes. Diabetes 40: 405-412

3. Levine M (1986) New concepts in the biology and biochemistry of ascorbic acid. N Engl J Med 314: 892-902

4. Chaterjee IB, Banerjee A (1979) Estimation of dehydroascorbic acid in blood of diabetic patients. Anal Biochem 98: 368-374

5. Som S, Basu D, Deb S et al. (1981) Ascorbic acid metabolism in diabetes mellitus. Metabolism 30: 572-577

6. Banerjee A (1982) Blood dehydroascorbic acid and diabetes mellitus in human beings. Ann Clin Biochem 19: 65-70

7. Stankova L, Riddle M, Larned J et al. (1984) Plasma ascorbate concentrations and blood cell dehydroascorbate transport in patients with diabetes mellitus. Metabolism 33: 347-353

8. Jennings PE, Chirico S, Jones AF, Lunec J, Barnett AH (1987) Vitamin C metabolites and microangiopathy. Diabetes Res 6: 151-154

9. Paolisso G, D'Amore A, Balbi V et al. (1994) Plasma vitamin $\mathrm{C}$ affects glucose homeostasis in healthy subjects and in non-insulin-dependent diabetics. Am $\mathrm{J}$ Physiol 266:E261-E268

10. Sinclair AJ, Taylor PB, Lunec J, Girling AJ, Barnett AH (1994) Low plasma ascorbate levels in patients with Type 2 Diabetes Mellitus consuming adequate dietary vitamin C. Diabet Med 11: 893-898

11. Yue DK, McLennan S, McGill M et al. (1990) Abnormalities of ascorbic acid metabolism and diabetic control: differences between diabetic patients and diabetic rats. Diabetes Res Clin Pract 9: 239-244

12. Sinclair AJ, Girling AJ, Gray L, Le Guen C, Lunec J, Barnett AH (1991) Disturbed handling of ascorbic acid in diabetic patients with and without microangiopathy during high dose ascorbate supplementation. Diabetologia 34: 171-175

13. Sinclair AJ, Girling AJ, Gray L, Lunec J, Barnett AH (1992) An investigation of the relationship between free radical activity and vitamin $\mathrm{C}$ metabolism in elderly diabetic subjects with retinopathy. Gerontology 38: 268-274

14. Chen MS, Hutchinson ML, Pecoraro RE, Lee WYL, Labbe RF (1983) Hyperglycaemia-induced intracellular depletion of ascorbic acid in human mononuclear leukocytes. Diabetes 32: 1078-1081

15. Kapeghian JC, Verlangieri AJ (1984) The effects of glucose on ascorbic acid uptake in heart endothelial cells: possible pathogenesis of diabetic angiopathies. Life Sci 34: 577-584

16. Mann GV, Newton P (1975) The membrane transport of ascorbic acid. Ann N Y Acad Sci 258: 243-252

17. Moser U, Weber F (1984) Uptake of ascorbic acid by human granulocytes. Int J Vitam Nutr Res 54: 47-53

18. Bernhanu P, Olefsky JM (1981) Effects of insulin and insulin like agents on the glucose transport system of cultured human fibroblasts. Diabetes 30: 523-529

19. McLennan S, Yue DK, Fisher E et al. (1988) Deficiency of ascorbic acid in experimental diabetes: relationship with collagen and polyol pathway abnormalities. Diabetes 37: 359-361

20. Yue DK, McLennan S, Fisher E et al. (1989) Ascorbic acid metabolism and polyol pathway in diabetes. Diabetes 38 : 257-261

21. Vinson JA, Staretz ME, Bose P, Kassm HM, Basalyga BS (1989) In vitro and in vivo reduction of erythrocyte sorbitol by ascorbic acid. Diabetes 38: 1036-1041

22. Cunningham JJ, Mearkle PL, Brown RG (1994) Vitamin C: an aldose reductase inhibitor that normalises erythrocyte sorbitol in insulin-dependent diabetes mellitus. Journal of the American College of Nutrition 13: 344-350

23. Khatami M, Suldan Z, David I, Weiye L, Rockey J (1988) Inhibitory effects of pyridoxal phosphate, ascorbate and aminoguanidine on nonenzymatic glycosylation. Life Sci 43: $1725-1731$

24. Stolba P, Streda M, Vondra K, Hatle K, Adam M (1988) Ascorbic acid inhibits nonenzymatic glycation of collagens type I, II, IV, V, IX, XI in vitro and renal basement membrane in vivo (Abstract). Diabetologia 31: 472A

25. Davie SJ, Gould BJ, Yudkin JS (1992) Effect of vitamin C on glycosylation of proteins. Diabetes 41: 167-173

26. Yew MS (1983) Effect of streptozotocin diabetes on tissue ascorbic acid and dehydroascorbic acid. Horm Metab Res 15: 158

27. Mitton KP, Dzialoszynski T, Sanford, SE, Trevithick JR (1997) Cysteine and ascorbate loss in the diabetic rat lens prior to hydration changes. Curr Eye Res 16: 564-571

28. Baird JD (1989) Relevance of the BB rat as a model for human insulin-dependent (Type 1) diabetes mellitus. In: Edwards CRW, Lincoln DW (eds) Recent Advances in Endo- 
crinology and Metabolism Vol 3, Churchill Livingstone, Edinburgh, pp.253-280

29. Young IS, Torney JJ, Trimble ER (1992) The effect of ascorbate supplementation on oxidative stress in the streptozotocin diabetic rat. Free Radic Biol Med 13: 41-46

30. Deutsch MJ, Weeks CE (1965) Microfluorimetric assay for vitamin C. J AOAC Int 48: 1248-3256

31. Brubacher G, Vuilleumier JP (1974) Vitamin C. In: Curtuis HCh, Roth M (eds) Clinical Biochemistry Vol 2, Walter de Gruyter, Berlin, pp.989-997

32. Vuilleumier JP, Keck E (1989) Fluorimetric assay of vitamin $\mathrm{C}$ in biological materials using a centrifugal analyser with fluorescence attachment. Journal of Micronutrient Analysis 5: 25-34

33. Ross MA (1994) Determination of ascorbic acid and uric acid in plasma by high-performance liquid chromatography. J Chromatogr B Biomed Appl 657: 197-200.

34. Stribling D, Mirrlees DJ, Harrison HE, Earl DCN (1985) Properties of ICI 128, 436, a novel aldose reductase inhibitor and its effects on diabetic complications in the rat. Metabolism 34: 336-344

35. Tames FJ, Baird JD, Bone AJ (1990) $\mathrm{HbA}_{1}$ in assessment of metabolic control in diabetic $\mathrm{BB} / \mathrm{E}$ rats. Diabetologia 33: $257-261$

36. DiMattio J (1992) Alterations in ascorbic acid transport into the lens of streptozotocin-induced diabetic rats and guinea pigs. Invest Opthalmol Vis Sci 33: 2926-2935

37. Lohman W (1987) Ascorbic acid and cataract. Ann N Y Acad Sci 498: 307-311
38. Vinson JA, Possanza CJ, Drack AV (1986) The effect of ascorbic acid on galactose-induced cataracts. Nutrition Reports International 33: 665-669

39. Kosengarten DC, Maher TJ (1978) Use of guinea pigs as model to study galactose-induced cataract formation. J Pharm Sci 10: 1478-1479

40. Gonzalez A-M, Sochor M, McLean P (1983) The effect of an aldose reductase inhibitor (Sorbinil) on the level of metabolites in lenses of diabetic rats. Diabetes 32: 482-485

41. Lou MF, Dickerson JE Jr, Garadi R, York BM Jr (1988) Glutathione depletion in the lens of galactosaemic and diabetic rats. Exp Eye Res 46: 517530

42. Blakytny R, Harding JJ (1992) Prevention of cataract in diabetic rats by aspirin, paracetamol (acetaminophen) and ibuprofen. Exp Eye Res 54: 509-518

43. Cameron NC, Cotter MA (1993) Potential therapeutic approaches to the treatment or prevention of diabetic neuropathy: evidence from experimental studies. Diabet Med 10: 593-605

44. Cameron NE, Cotter MA, Maxfield EK (1993) Antioxidant treatment prevents the development of peripheral nerve dysfunction in streptozotocin-diabetic rats. Diabetologia 36: 299-304

45. Cotter MA, Love A, Watt MJ, Cameron NE, Dines KC (1995) Effects of natural free radical scavengers on peripheral nerve and neurovascular function in diabetic rats. Diabetologia 38: 1285-1294

46. Rivers JM (1987) Safety of high-level vitamin C ingestion. Ann N Y Acad Sci 498: 445-454 